\title{
Antipruritic Effect of Cnidii Monnieri Fructus (Fruits of Cnidium monnieri Cusson)
}

\author{
Hideaki Matsuda, ${ }^{*, a}$ Yasuko Ido, ${ }^{a}$ Atsushi Hirata,${ }^{a}$ Yoshiaki Ino, ${ }^{a}$ Shunsuke Naruto, ${ }^{a}$ \\ Tsutomu AмамiYa, ${ }^{b}$ and Michinori KuBo ${ }^{a}$ \\ Faculty of Pharmaceutical Sciences, Kinki University, ${ }^{a}$ 3-4-1 Kowakae, Higashiosaka, Osaka 577-8502, Japan and \\ Daiichi Pharmaceutical Co., Ltd., 3-14-10 Nihonbashi, Chuo-ku, Tokyo 103-8234, Japan. \\ Received June 27, 2001; accepted October 4, 2001
}

\begin{abstract}
Antipruritic effects of $\mathbf{7 0} \%$ ethanol extract (CM-ext) of Cnidii Monnieri Fructus (dried fruits of Cnidium monnieri Cusson, Umberifferae) were investigated. In mice, an oral administration of CM-ext (200 and $500 \mathrm{mg} / \mathrm{kg}$ ) inhibited compound 48/80-induced scratching behavior without influence on spontaneous locomotion. Isopimpinellin (3) and osthol (1), coumarin derivatives isolated from CM-ext, showed an inhibitory effect on compound $48 / 80$-induced scratching behavior.
\end{abstract}

Key words Cnidium monnieri; antipruritic effect; isopimpinellin; osthol

Pruritus is discomfort cutaneous sensation for patients having a skin disorder such as atopic dermatitis, and is often accompanied by scratching behavior. Antihistaminic, steroid and antiallergic drugs are used for the treatment of pruritus. During the course of our studies seeking antipruritic agents from natural resources, we developed an experimental mice model to treat a number of samples in a short time to evaluate the antipruritic effect. ${ }^{1)}$ Using this model, namely compound 48/80-induced scratching behavior in ddY-mice, several herb medicines whose antipruritic effect was expected from various herbal literature were screened. Among them, Kochiae Fructus (dried fruits of Kochia scoparia L.) and Cnidii Monnieri Fructus (dried fruits of Cnidium monnieri Cusson) were found to exhibit an antipruritic effect. Momordin Ic, an oleanane-type saponin, isolated from Kochiae Fructus was ascertained to be one of the active components. ${ }^{1)}$ Recently, Basnet et $a l .^{2)}$ reported that a mixture of coumarin derivatives obtained from Cnidii Monnieri Fructus exhibited an antipruritic action on substance P-induced itching model ICR mice. However, inhibition of compound 48/80-induced scratching behavior in ddY mice by $70 \%$ ethanol extract (CM-ext) of Cnidii Monnieri Fructus has not been investigated in detail. The object of this report ${ }^{3)}$ is to examine the antipruritic components of CM-ext using compound 48/80induced itching model mice.

\section{MATERIALS AND METHODS}

Plant Material Cnidii Monnieri Fructus (dried fruits of Cnidium monnieri Cusson produced in China) was purchased from Yamada Yakken Co., Ltd. Pharmacy (Osaka) in 1999. A voucher specimen has been deposited at Kinki University, Osaka, (voucher number: CM-99001).

Preparation of CM-ext from Cnidii Monnieri Fructus The crushed fruits $(500 \mathrm{~g})$ of Cnidium monnieri were extracted twice with $70 \%$ EtOH (5l each) under reflux for $1 \mathrm{~h}$. The combined filtrates were concentrated under reduced pressure and lyophilized to give a brown powder (CM-ext) (73.7 g, yield; $14.7 \%$ ).

Fractionation of CM-ext and Isolation of Osthol (1), Imperatorin (2), and Isopimpinellin (3) Melting points were determined on a Yanagimoto micro melting point appa- ratus without correction. All chemical reagents were reagent grade and were purchased from Wako Pure Chemical Industries, Ltd. (Osaka), unless otherwise noted. The CM-ext $(53.7 \mathrm{~g})$ was suspended in water and then extracted successively with hexane, EtOAc, and 1-BuOH. After solvent extraction, the aqueous layer was concentrated under reduced pressure and lyophilized to afford an aqueous soluble fraction (26.7 g) (Chart 1). The hexane extract was dried over $\mathrm{Na}_{2} \mathrm{SO}_{4}$ and concentrated. The resulting crystalline precipitate $(2.47 \mathrm{~g})$ was collected by filtration, and its mother liquor was concentrated to give a hexane soluble fraction $(3.9 \mathrm{~g})$. The EtOAc extract was dried over $\mathrm{Na}_{2} \mathrm{SO}_{4}$ and concentrated to give an EtOAc soluble fraction $(9.9 \mathrm{~g})$. The $1-\mathrm{BuOH}$ extract was concentrated to give a $1-\mathrm{BuOH}$ soluble fraction $(3.9 \mathrm{~g})$. Antipruritic activity of each fraction was assayed by the compound 48/80-induced scratching behavior method described below. The data are shown in Chart 1 . The most active crystalline precipitate $(2.3 \mathrm{~g})$ exhibiting three main spots on TLC [silica gel 60 F254 (Merck No. 1.05735), solvent system; hexane-EtOAc $(3: 1 \mathrm{v} / \mathrm{v})$, detection; UV] was chromatographed on silica gel (No. 1.07734, Merck, Darmstadt, Germany) eluted with a gradient of hexane and EtOAc. The eluent was separated into 5 fractions (Fraction 1-5) by monitoring with TLC. Fraction 1 was recrystallized from diethyl ether-hexane to give osthol (1), $756 \mathrm{mg}$, colorless prisms, $\mathrm{mp}$ $82-83^{\circ} \mathrm{C}$. Fraction 3 was purified by rechromatography on silica gel (No. 1.05735, Merck, Darmstadt, Germany) eluted with benzene-EtOAc $(10: 1 \mathrm{v} / \mathrm{v})$ and recrystallization from EtOAc-hexane to give imperatorin (2), $95 \mathrm{mg}$, colorless needles, mp $97-98^{\circ} \mathrm{C}$. Fraction 5 was recrystallized from EtOH-hexane to give isopimpinellin (3), $48 \mathrm{mg}$, pale yellow needles, mp $139-141^{\circ} \mathrm{C}$. The known compounds (1, 2, and 3) whose chemical structures are depicted in Fig. 1 were identified by comparison of their physical data (mp, IR, ${ }^{1} \mathrm{H}-$ and ${ }^{13} \mathrm{C}-\mathrm{NMR}$ ) with reported values. ${ }^{4-7)}$

Pharmacological Test Animals Male Wistar rats $(180-200 \mathrm{~g})$, male ddY mice $(26-28 \mathrm{~g})$, and male Hartley guinea pigs $(200-250 \mathrm{~g})$ were provided by SLC (Japan SLC, Hamamatsu). They were maintained in an air-conditioned room with lighting from 7 a.m. to 7 p.m. The room temperature (about $23^{\circ} \mathrm{C}$ ) and humidity (about $60 \%$ ) were controlled automatically. Laboratory pellet chows (Labo MR Stock and 


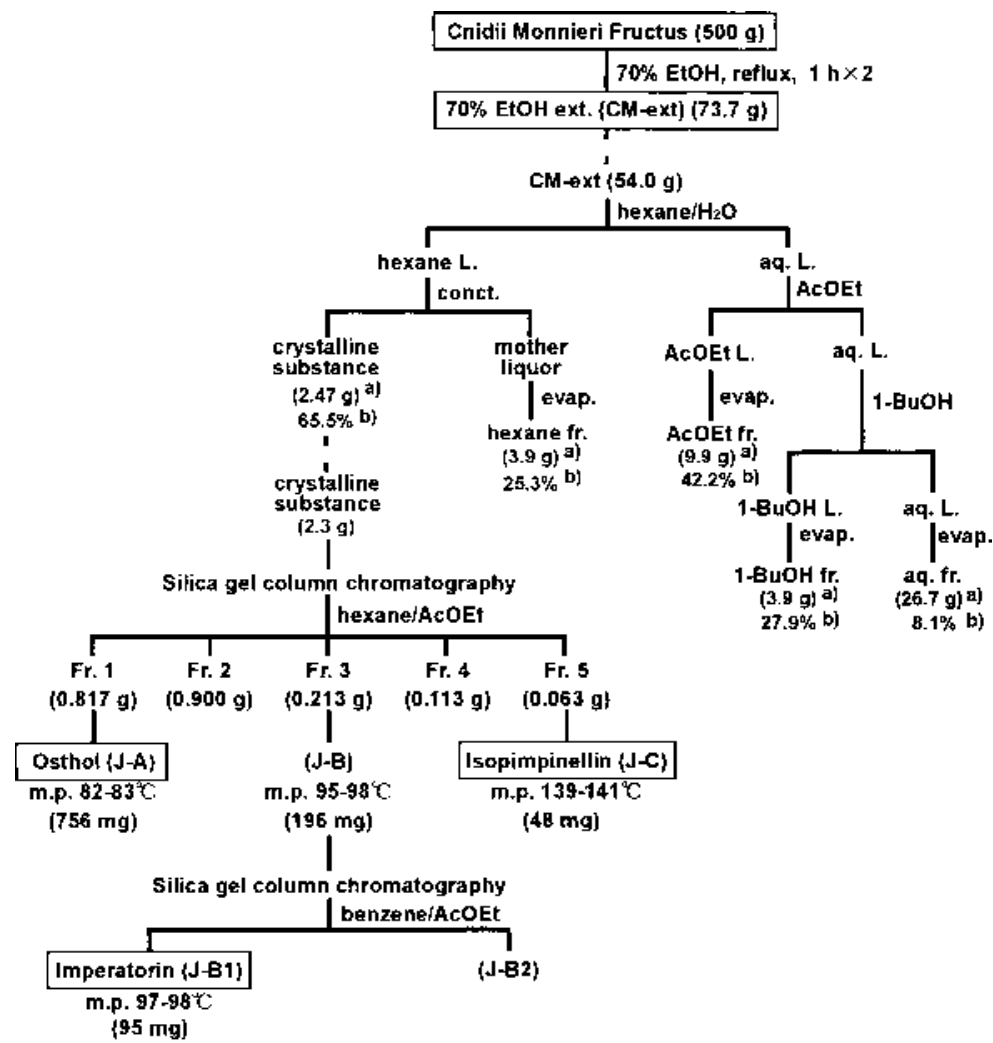

Chart 1. Extraction and Fractionation from Cnidii Monnieri Fructus and Antipruritic Activity of Each Fraction and Isolation of Osthol, Imperatorin and Isopimpinellin

a) Yield from CM-ext (54.0 g). b) Inhibition \% at $100 \mathrm{mg} / \mathrm{kg}$ (p.o.).

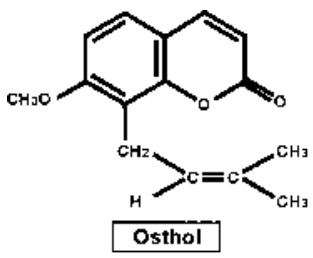

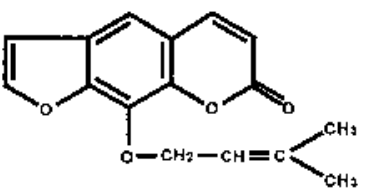

Imperatorin

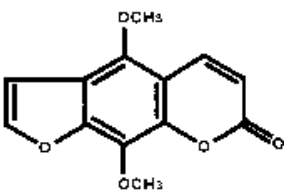

Isopimpinellin

Fig. 1. Coumarin Derivatives Isolated from Cnidii Monnieri Fructus

Labo R stock, Nihon Nosan Kogyo K.K., Yokohama) and water were freely available.

Drugs The following drugs were used in this study: compound 48/80 (Sigma, St. Louis, U.S.A.), histamine dihydrochloride (histamine, Nacalai Tesque, Kyoto), diphenhydramine hydrochloride (diphenhydramine, Tokyo Kasei, Tokyo), sodium cromoglycate (SCG, Funakoshi, Tokyo), Ficoll (Nacalai Tesque), and Hanks' solution (Research Foundation for Microbial Disease of Osaka University, Suita).

Compound 48/80-Induced Scratching Behavior in Mice Scratching behavior was induced by the subcutaneous injection of $0.1 \%$ compound $48 / 80$ in saline at $100 \mu \mathrm{l} /$ site into the back of male ddY mice ( $n=12-14$ per group). ${ }^{1)}$ Scratching on the injected site by the hind paws was counted for $10 \mathrm{~min}$, and that at other sites such as the ears was disregarded. Each test sample was given orally $1 \mathrm{~h}$ before the compound $48 / 80$ injections. As a control, mice were orally administered $0.2 \%$ sodium carboxymethyl cellulose $(\mathrm{CMC} \cdot \mathrm{Na})$ and injected s.c. with compound 48/80. Diphenhydramine was used as a reference drug.

Spontaneous Locomotion in Mice To habituate a ddY mouse to new surroundings, the animal was placed in a doughnut-shaped cage (Laboratory Ambulometer, Model SMA-10, OHC O’Hara \& Co., Ltd., Kyoto) $30 \mathrm{~min}$ after the oral administration of sample. After $30 \mathrm{~min}$, changes in spontaneous locomotor activity were recorded with a Drincorder (GI-77115, OHC O'Hara \& Co., Ltd.) for a $1 \mathrm{~h}$ period.

Compound 48/80-Induced Histamine Release from Rat Peritoneal Mast Cells Mast cells were prepared from the peritoneal cavity fluid of male rats by a slight modification of the method described by Uvnäs and Thon. ${ }^{8)}$ The cells were suspended in Hanks' solution containing heparin $(10 \mathrm{U} / \mathrm{ml})$, then layered on $40 \%$ Ficoll in a test tube for $30 \mathrm{~min}$. After centrifugation at $150 \times \boldsymbol{g}$ and $4{ }^{\circ} \mathrm{C}$ for $10 \mathrm{~min}$, the layer containing mast cells was pipetted out. The cells were washed three times with $5 \mathrm{ml}$ of phosphate-buffered saline $(\mathrm{pH} 7.0)$ and suspended in the same medium at $2.9 \times 10^{6}$ cells $/ \mathrm{ml}$. The cell suspensions contained $85-90 \%$ or more viable mast cells, as determined by the toluidine blue $(0.1 \%$ in $50 \%$ EtOH) staining test of Bray and Van Arsdel. ${ }^{9}$ )

The test substances dissolved with 5\% dimethyl sulfoxide (DMSO) were added to the mast cell suspension, and then 


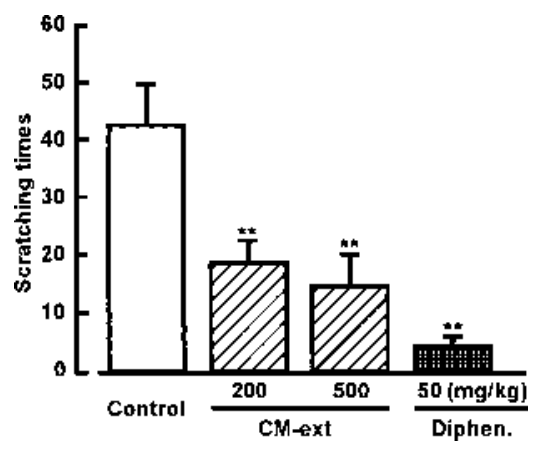

Fig. 2. Effects of $70 \%$ Ethanol Extract from Cnidii Monnieri Fructus (CM-ext) and Diphenhydramine (Diphen.) on Compound 48/80-Induced Scratching Behavior in Mice

Mice were dosed orally with test substances suspended in $0.2 \% \mathrm{CMC} \cdot \mathrm{Na} 1 \mathrm{~h}$ before subcutaneous injection of compound $48 / 80(100 \mathrm{mg} /$ mouse). Immediately after the injection, the times of scratching were counted over a $10 \mathrm{~min}$ period. Each value represents the mean \pm S.E. $(n=12-14)$. Significantly different from control at $* *: p<0.01$.

the mixture was incubated at $37^{\circ} \mathrm{C}$. After $10 \mathrm{~min}, 0.1 \mathrm{ml}$ of compound $48 / 80$ solution $(0.2 \mathrm{mg} / \mathrm{ml})$ was added, and the mixture was incubated at $37^{\circ} \mathrm{C}$ for $10 \mathrm{~min}$ in a final volume of $2 \mathrm{ml}$. Cooling the mixture on ice terminated the reaction. The mixture was centrifuged at $150 \times \boldsymbol{g}$ and $5^{\circ} \mathrm{C}$ for $5 \mathrm{~min}$, then histamine in the supernatant fluid was assayed fluorometrically according to the method of Shore $e a^{a l}{ }^{10)}$ The activity of the test substance on histamine release from mast cells induced by compound 48/80 was expressed as histamine release percentage. SCG was used as a reference drug.

Measurement of Histamine-Induced Contraction in Isolated Guinea Pig Ileum A guinea pig was sacrificed by a blow on the head and the ileum was isolated. A length of 1.5 to $2.0 \mathrm{~cm}$ was suspended in Tyrode's solution bubbled through with air in an organ bath maintained at $37^{\circ} \mathrm{C}$. Ileum contractions were isotonically recorded by means of a lever loaded with $0.5 \mathrm{~g}$ on a slmoke drum. The ileum was preincubated with CM-ext $\left(10^{-4} \mathrm{~g} / \mathrm{ml}\right)$ dissolved in $5 \%$ DMSO/Tyrode's solution or diphenhydramine $\left(3 \times 10^{-7} \mathrm{M}\right)$ dissolved in Tyrode's solution for $3 \mathrm{~min}$, and then histamine $\left(10^{-10}\right.$ $10^{-5} \mathrm{M}$ ) was added and incubation was carried out for $3 \mathrm{~min}$ at $37^{\circ} \mathrm{C}$. The extent of contraction was estimated from the maximal contraction of the isolated ileum after the addition of histamine alone.

Statistical Analysis The experimental data were tested for statistically significant differences by Bonferroni/Dunn's method (Multiple Range Test).

\section{RESULTS}

Effect of CM-ext on Compound 48/80-Induced Scratching Behavior CM-ext (200 and $500 \mathrm{mg} / \mathrm{kg}$, p.o.) inhibited the scratching behavior caused by compound $48 / 80$ without influence on spontaneous locomotion. Diphenhydramine $(50 \mathrm{mg} / \mathrm{kg}$, p.o. $)$ also showed such as inhibitory effect without influence on spontaneous locomotion.

Effect of CM-ext on Spontaneous Locomotion CM-ext (200 and $500 \mathrm{mg} / \mathrm{kg}$, p.o.) did not change the spontaneous locomotor activity of 10 mice per group. (Data not shown)

Effect of CM-ext on Compound 48/80-Induced Histamine Release Treatment with CM-ext $(50,200,500 \mathrm{mg} /$ $\mathrm{ml}$ ) significantly suppressed the histamine release. A refer-

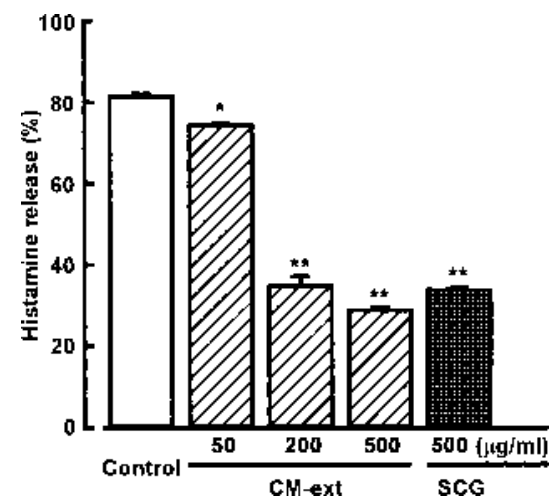

Fig. 3. Effects of $70 \%$ Ethanol Extract from Cnidii Monnieri Fructus (CM-ext) and Sodium Cromoglycate (SCG) on Compound 48/80-Induced Histamine Release from Peritoneal Mast Cells of Rats

Mast cells prepared from the peritoneal cavity fluid of rats were suspended in phosphate-buffered saline at $2.9 \times 10^{6}$ cells $/ \mathrm{ml}$. The mast cell suspensions treated with $\mathrm{CM}$ ext or SCG were stimulated by compound $48 / 80(10 \mathrm{mg} / \mathrm{ml})$. Each value represents the mean \pm S.E. $(n=3)$. Significantly different from control at $*: p<0.05, * *: p<0.01$.

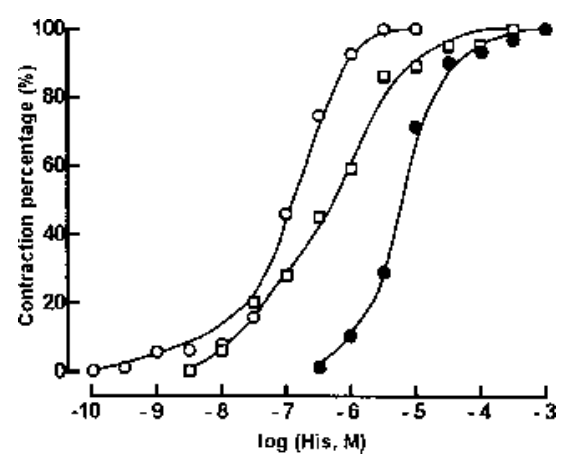

Fig. 4. Effects of $70 \%$ Ethanol Extract from Cnidii Monnieri Fructus (CM-ext) and Diphenhydramine on the Concentration-Action Curves of Phasic Concentration by Histamine with the Isolated Ileum of Guinea Pig

$\bigcirc$, control; $\square, \mathrm{CM}$-ext $10^{-4} \mathrm{~g} / \mathrm{ml} ; \bullet$, diphenhydramine $3 \times 10^{-7} \mathrm{M}$. Each value represents the mean of 3 experiments.

ence drug, SCG, at a concentration of $500 \mu \mathrm{g} / \mathrm{ml}$ also inhibited the release.

Effect of CM-ext on Histamine-Induced Contraction in Isolated Ileum In the experiment shown in Fig. 4, histamine by itself caused the contraction of isolated guinea pig ileum with an S-shaped $\log ($ dose $)$-response curve at concentration of $10^{-10}-10^{-5} \mathrm{M}$. A reference compound, diphenhydramine $\left(3 \times 10^{-7} \mathrm{M}\right)$ showed a competitive antagonistic effect. In the presence of CM-ext $\left(10^{-4} \mathrm{~g} / \mathrm{ml}\right)$, the dose-response curve was shifted to the right but altered slightly in shape.

Antipruritic Activity of Coumarin Derivatives Three known coumarin derivatives, osthol (1), imperatorin (2), and isopimpinellin (3), were isolated from CM-ext. On the antipruritic assay results shown in Table 1, isopimpinellin (3) was found to be an active constituent, whereas osthol (1) was less active than $\mathbf{3}$, and imperatorin (2) was ineffective.

\section{DISCUSSION}

Kuraishi et al. ${ }^{11)}$ reported that scratching behavior is caused dose-dependently by a dorsal subcutaneous injection of compound $48 / 80^{12)}$ in ddY male mice. It is well known that compound $48 / 80$ releases many chemical mediators 
Table 1. Effects of Coumarin Derivatives Isolated from Cnidii Monnieri Fructus and Diphenhydramine on Compound 48/80-Induced Scratching Behavior in Mice

\begin{tabular}{lrcc}
\hline \hline \multicolumn{1}{c}{ Treatment } & $\begin{array}{c}\text { Dose } \\
(\mathrm{mg} / \mathrm{kg})\end{array}$ & $\begin{array}{c}\text { Scratching } \\
\text { times }\end{array}$ & $\begin{array}{c}\text { Inhibition } \\
(\%)\end{array}$ \\
\hline Control & - & $41.1 \pm 6.0$ & - \\
Osthol & 20 & $26.8 \pm 4.0^{*}$ & 34.7 \\
& 50 & $27.3 \pm 4.5^{*}$ & 33.6 \\
Diphenhydramine & 100 & $27.5 \pm 5.0^{*}$ & 33.1 \\
& 50 & $4.4 \pm 1.7^{* *}$ & 89.3 \\
Control & - & $44.6 \pm 3.5$ & -8.1 \\
Imperatorin & 20 & $48.2 \pm 7.1$ & 11.0 \\
& 50 & $39.7 \pm 5.0$ & 5.2 \\
Isopimpinellin & 100 & $42.3 \pm 6.5$ & 40.6 \\
& 20 & $26.5 \pm 7.8^{*}$ & 39.9 \\
& 50 & $26.8 \pm 5.4^{*}$ & 63.7 \\
Diphenhydramine & 50 & $16.2 \pm 3.4^{* *}$ & 93.3 \\
\hline
\end{tabular}

Mice were dosed orally with the test substances suspended in $0.2 \% \mathrm{CMC} \cdot \mathrm{Na} 1 \mathrm{~h}$ be fore subcutaneous injection of compound $48 / 80(100 \mu \mathrm{g} /$ mouse). Immediately after the injection, the times of scratching were counted over a $10 \mathrm{~min}$ period. Each value reprersents the mean \pm S.E. $(n=8-12)$. Significantly different from the control at $*: p<0.05, * *: p<0.01$

from mast cell. ${ }^{13-16)}$ Although histamine is the major chemical mediator inducing itching, histamine did not induce scratching behavior in ddY mice as described in the previous paper. ${ }^{1)}$

CM-ext significantly inhibited compound 48/80-induced scratching behaviors of ddY mice without influence on spontaneous locomotion. Cnidii Monnieri Fructus has been used to treat pain in female genitalia, impotence and suppurative dermatosis as an antipruritogenic agent in ancient China. Cnidii Monnieri Fructus has been reported to show antiallergic, ${ }^{17)}$ androgenic ${ }^{18)}$ and antibacterial ${ }^{6}$ activities. Recently, Basnet et ll. $^{2)}$ reported that a so-called CS-3 fraction obtained from a methanol extract of Cnidii Monnieri Fructus showed an antipruritic action on the substance P-induced itching model of ICR mice, and that this effect may be due to additive or synergistic action of several coumarin derivatives, such as xanthotoxin, isopimpinellin, bergapten, imperatorin, osthol, and unidentified minor compounds.

The active components of CM-ext were isolated by activity guided fractionation and column chromatography monitoring with the inhibitory effect on compound 48/80-induced scratching behavior. An active principle was found to be a furocoumarin, isopimpinellin (3). Osthol (1) did not show any significant effect on substance P-induced itching model of ICR mice, ${ }^{2)}$ but showed a relatively strong inhibitory effect on compound 48/80-induced scratching behavior in $\mathrm{ddY}$ mice. These results implied that there are some mechanistic differences between these two itching animal models due to the inducing agents and/or strains of mice. Coumarin derivatives, 1, 2 and 3, were isolated earlier from Cnidium monnieri, ${ }^{6)}$ but antipruritic activities of $\mathbf{1}$ and $\mathbf{3}$ on compound 48/80-induced itching model mice were found for the first time.

Some attempts to examine the biochemical inhibition mechanism of compound 48/80-induced scratching behavior by CM-ext revealed that CM-ext showed the inhibitory effects on release of histamine from mast cells induced by compound $48 / 80$, and on the contraction of the excised guinea pig ileum induced by histamine. However, the question of whether the inhibitory effects of CM-ext are directly correlated with histamine during the course of compound 48/80-induced scratching behavior in ddY mice remains unanswered. Further detailed studies on the inhibition mechanism of CM-ext, $\mathbf{1}$ and $\mathbf{3}$ are in progress.

\section{REFERENCES}

1) Kubo M., Matsuda H., Dai Y., Ido Y., Yoshikawa M., Yakugaku Zasshi, 117, 193-201 (1997).

2) Basnet P., Yasuda I., Kumagai N., Tohda C., Nojima H., Kuraishi Y., Komatsu K., Biol. Pharm. Bull., 24, 1012-1015 (2001).

3) This work was presented at the 121st Annual Meeting of the Pharmaceutical Society of Japan, Sapporo, March 2001. Abstracts of Papers 2, p. 102 .

4) Hata K., Kozawa M., Baba K., Yakugaku Zasshi, 92, 1289-1294 (1972).

5) Murray R. D. H., Ballantyne M. M., Mathai K. P., Tetrahedron, 27, 1247-1251 (1971).

6) Honda G., Tabata M., Baba K., Kozawa M., Shoyakugaku Zasshi, 38, $221-226$ (1984).

7) Elgamal M. H. A., Elewa N. H., Elkhrisy E. A. M., Duddeck H., Phytochemistry, 18, 139-143 (1979).

8) Uvnäs B., Thon I. L., Exp. Cell Res., 18, 512-520 (1959).

9) Bray R. E., Van Arsdel P. P., Proc. Soc. Exp. Biol. Med., 106, 255259 (1961).

10) Shore P. A., Burkhalter A., Cohn V. H., J. Pharmacol. Exp. Ther., 127, 182-186 (1959).

11) Kuraishi Y., Nagasawa T., Hayashi K., Satoh M., Eur. J. Pharmacol., 275, 229-233 (1995).

12) Paton W. D. M., Pharmacol. Rev., 19, 269-328 (1957).

13) Parratt J. R., West G. B., J. Physiol., 137, 169-178 (1957).

14) Moran N. C., Uvnäs B., Westerholm B., Acta Physiol. Scand., 56, 2641 (1962).

15) Prourost-Danon A., Peixoto J. M., Javierre M. Q., Immunology, 15, 271-286 (1968)

16) Cabut M., Haegermark Ö., Acta Physiol. Scand., 68, 206-214 (1966).

17) Yamahara J., Kozuka M., Sawada T., Fujimura H., Nakano K., Tomimatsu T., Nohara T., Chem. Pharm. Bull., 33, 1676-1680 (1985).

18) Shinohara T., Nakajima Y., Ikegami R., Matsumura T., Mizuno I., Ogita Z., J. Trad. Med., 11, 410-411 (1994). 